\title{
Aminoglycoside Binding to the Hammerhead Ribozyme: A General Model for the Interaction of Cationic Antibiotics with RNA
}

\section{Thomas Hermann and Eric Westhof*}

Institut de Biologie Moléculaire et Cellulaire du CNRS, 15 rue René Descartes

F-67084, Strasbourg, France
A variety of drugs inhibit biological key processes by binding to a specific RNA component. We focus here on the well-analysed hammerhead ribozyme RNA that is inhibited by aminoglycoside antibiotics, a process considered as a paradigm for studying drug/RNA interactions. With insight gained from molecular dynamics simulations of the ribozyme in the presence of $\mathrm{Mg}^{2+}$ identified by crystallography and of aminoglycosides in solution, a general model for aminoglycoside binding to RNA is proposed. A striking structurally based complementarity between the charged ammonium groups of the aminoglycosides and the metal binding sites in the hammerhead was uncovered. Despite dynamical flexibility of the aminoglycosides, several of the intramolecular distances between the charged ammonium groups of the drugs were found to be rather constant. Intramolecular ammonium distances of the aminoglycosides span ranges similar to the interionic distances between $\mathrm{Mg}^{2+}$ in the hammerhead. Successful docking of aminoglycosides to the hammerhead ribozyme could be achieved by positioning the ammonium groups at the sites occupied by $\mathrm{Mg}^{2+}$. The covalently linked ammonium groups of the aminoglycosides are thus able to complement in space the negative electrostatic potential created by a three-dimensional RNA fold. Consequently, it is suggested that aminoglycoside-derived sugars could constitute a basic set of yardstick synthons ideal for rational and combinatorial synthesis of drugs targeted at biologically relevant RNA folds.

(C) 1998 Academic Press Limited

Keywords: drug design; metal ion binding sites; molecular dynamics simulations; neomycin

\section{Introduction}

The function of many antibiotics is based on the inhibition of a central biological process by binding of the drug to a specific RNA (Gale et al., 1981). Aminoglycoside antibiotics (Figure 1(a)) are intensively studied because they are widely used in therapy and are known to interact with a large variety of different RNA targets. The neomycins bind to functional sites in the $16 \mathrm{~S}$ ribosomal RNA and cause miscoding and translocation arrest of the ribosome (Moazed \& Noller, 1987). Neomycin B inhibits also human immunodeficiency virus (HIV) replication in vivo by selectively blocking the binding of the Rev protein to its viral RNA target (Zapp et al., 1993). Other RNA-catalysed processes

Abbreviations used: HIV, human immunodeficiency virus; $\mathrm{HDV}$, hepatitis delta virus; $\mathrm{MD}$, molecular dynamics; RMS, root-mean-square. found to be inhibited by aminoglycoside antibiotics include the self-splicing of group I introns (von Ahsen et al., 1991), the cleavage reactions of the hammerhead ribozyme (Stage et al., 1995) and the hepatitis delta virus (HDV) ribozyme (Rogers et al., 1996).

Our structural understanding of specific aminoglycoside binding to RNA has recently progressed following publication of two NMR structures of aminoglycoside/RNA complexes (Jiang et al., 1996; Fourmy et al., 1996) and the results obtained by applying various techniques to study aminoglycoside/RNA interaction (Wang \& Rando, 1995; Wallis et al., 1995; Werstuck et al., 1996; Famulok \& Hüttenhofer, 1996; Hendrix et al., 1997; Wang \& Tor, 1997a,b). Biochemical data suggest that the inhibitory effect of neomycin on the hammerhead ribozyme is based on competitive binding to the RNA between the polycationic aminoglycoside and the $\mathrm{Mg}^{2+}$ (Clouet-d'Orval et al., 1995), which are 

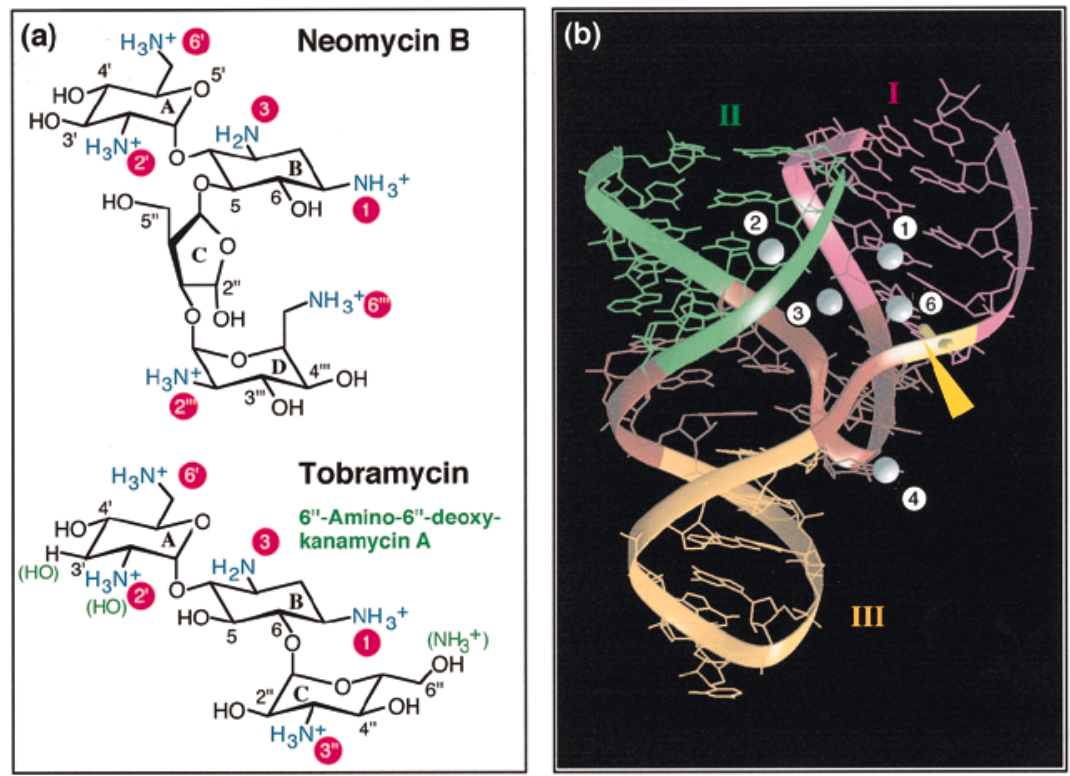

Figure 1. (a) Structures of the antibiotics neomycin $B$, tobramycin and 6"-Amino-6"-deoxykanamycin A, substituted 2-deoxystreptamine aminoglycosides that inhibit the hammerhead ribozyme cleavage reaction. Neomycin B is a strong inhibitor markedly reducing hammerhead catalysis at drug concentrations of $0.1 \mathrm{mM}$, while the kanamycin deivative and tobramycin are moderate inhibitor at concentrations of $1 \mathrm{mM}$ (Wang \& Tor, 1997b; Clouet-d'Orval et al., 1995; Schroeder \& von Ahsen, 1997). At neutral $\mathrm{pH}$ five of the six amino groups in neomycin with $\mathrm{pK}_{\mathrm{a}}$ values between 7.6 and 8.8 are protonated while the amino group at position 3 has a $\mathrm{p} K_{\mathrm{a}}$ value of 5.7 (Botto \& Coxon, 1983). (b) Threedimensional structure of the hammerhead ribozyme as determined by crystal structure analysis (Scott et al., 1996). Five $\mathrm{Mg}^{2+}$ bound to the RNA are shown as spheres numbered in agreement with Scott et al. (1996). The $\mathrm{Mg}^{2+}$ at site 6 is directly bound to the anionic pro- $\mathrm{R}_{\mathrm{P}}$ oxygen atom of the cleavable phosphate group, which is marked in yellow.

required for both folding and catalysis (Dahm \& Uhlenbeck, 1991; Long et al., 1995). The structure of the antibiotic plays an important role in specific binding to the hammerhead RNA, since other polycations, like the polyamine spermine, do not inhibit catalysis at comparable concentrations (Dahm \& Uhlenbeck, 1991).

Despite its probable biological irrelevance, we consider the inhibition of the hammerhead ribozyme a paradigm process to elucidate structural details of the interaction of a catalytical RNA with aminoglycosides for two reasons. First, because of the availability of crystal structures for this RNA (Pley et al., 1994; Scott et al., 1995, 1996). Second, considering biochemical data that suggest that, upon binding of the polycationic aminoglycosides to the hammerhead RNA, the charged ammonium groups of the antibiotic displace competitively several of the $\mathrm{Mg}^{2+}$ bound to the RNA (Clouetd'Orval et al., 1995). At neutral $\mathrm{pH}$ the amino groups in the aminoglycosides are predominantly protonated (Jiang et al., 1996; Botto \& Coxon, 1983; Szilagyi et al., 1993). Neomycin B competes for binding to the hammerhead with about five $\mathrm{Mg}^{2+}$ (Clouet-d'Orval et al., 1995). Among those are the $\mathrm{Mg}^{2+}$ necessary for catalysis, the displacement of which leads to inhibition of the ribozyme. The positions of five $\mathrm{Mg}^{2+}$ bound to the hammerhead RNA were recently determined by crystal structure analysis of a flash-frozen active hammerhead ribozyme (Scott et al., 1996; Figure 1b). One of these cations is directly bound to the pro- $\mathrm{R}_{\mathrm{P}}$ oxygen atom of the cleavable phosphate group consistent with findings from phosphorthioate interference analysis (Knöll et al., 1997). Recently, this metal along with a second $\mathrm{Mg}^{2+}$ in close proximity was suggested to form a $\mu$-hydroxo-bridged magnesium cluster providing the hydroxide group able to activate the attacking 2'-hydroxyl group in the cleavage reaction (Hermann et al., 1997).

Using molecular modeling and molecular dynamics simulations based on the crystal structure of the active hammerhead RNA (Scott et al., 1996), we derive plausible three-dimensional models of aminoglycoside/hammerhead complexes that we suggest illustrate new concepts integrating the knowledge and experimental data available on antibiotic/RNA binding modes.

\section{Results}

\section{Intramolecular distances between aminoglycoside ammonium groups resemble distances between $\mathrm{Mg}^{2+}$ binding sites in the hammerhead RNA.}

We hypothesized that aminoglycoside binding to the hammerhead RNA is a structurally specific process due to a defined arrangement of charged ammonium groups in the antibiotic resembling that formed by the $\mathrm{Mg}^{2+}$ bound in the central pocket of the wishbone hammerhead three-dimensional structure. In order to test this hypothesis, we monitored the intramolecular distances between the amino groups in aminoglycoside antibiotics during molecular dynamics (MD) simulations and compared them with the values obtained for the interionic distances between the $\mathrm{Mg}^{2+}$ identified in the hammerhead crystal structure. To account for changes in the distances between amino groups due to dynamic conformational changes in the antibiotics, the accessible conformational space was explored by MD simulations on solvated amino- 

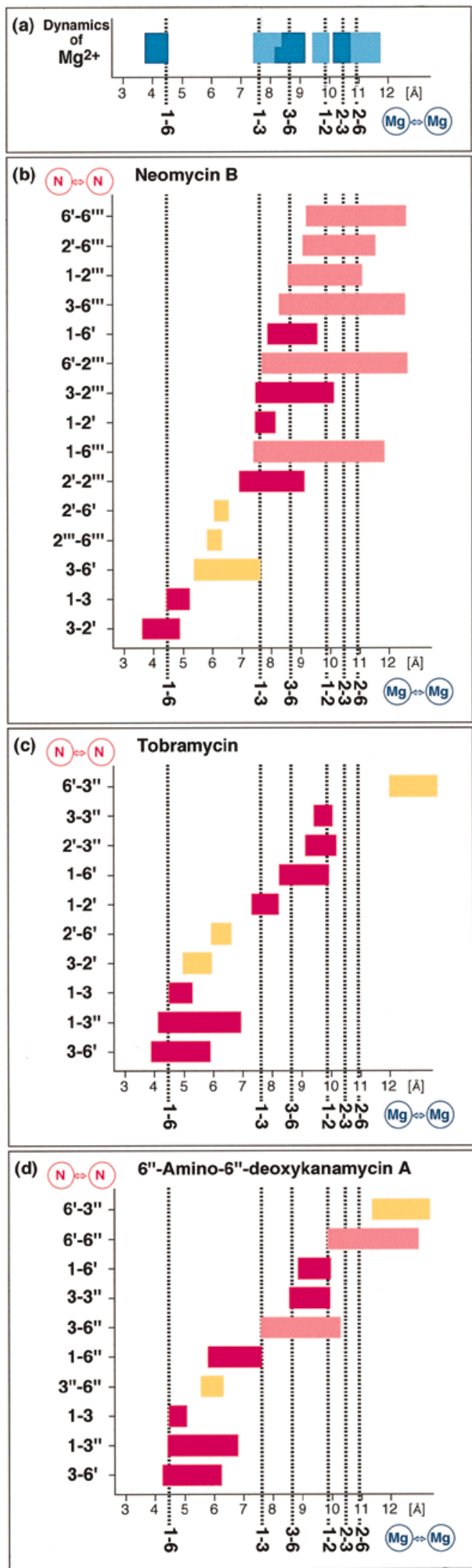

Figure 2. Dynamical range of (a) interionic distances between $\mathrm{Mg}^{2+}$ in the hammerhead RNA and ((b) to (d)) intramolecular distances between ammonium groups in (b) neomycin B, (c) tobramycin and (d) the kanamycin derivate observed during MD simulations. Along the glycosides at $300 \mathrm{~K}$ and at $600 \mathrm{~K}$. For the calculations, we chose neomycin B, a 4,5-disubstituted deoxystreptamine and strong hammerhead inhibitor, and the moderate hammerhead inhibitors tobramycin and 6"-amino-6"-deoxykanamycin A, both 4,6-disubstituted deoxystreptamines (Clouetd'Orval et al., 1995; Wang \& Tor, 1997a,b; Schroeder \& von Ahsen, 1997; Figure 1(a)).

Similarly, we recorded the range of inter-magnesium distances observed during MD simulations of the hammerhead RNA crystal structure (Scott et al., 1996; Figure 2(a)). As described previously, the four $\mathrm{Mg}^{2+}$ located in the cavity, formed by the facing deep grooves of stems I and II (Figure 1(b)), stayed around their binding sites in the crystal structure during MD simulations (Hermann et al., 1997). The cation at site 6 is bound to the pro- $R_{P}$ oxygen atom of the cleavable phosphate while the metals at the sites 1,3 and 2 are, respectively, 7, 11 and $14 \AA$ away from the cleavable phosphate group.

A broad range of aminoglycoside conformations was sampled during MD simulations during which inter-ammonium distances were monitored (Figure 2). The mutual orientation of rings A and B was relatively rigid in the antibiotics while, for neomycin, rings $\mathrm{C}$ and $\mathrm{D}$ displayed increased flexibility. Despite RMS deviations ranging up to $4 \AA$ between different aminoglycoside conformers, distinct sets of constant distances between ammonium groups were systematically observed in all three drugs. An overlay plot of the recorded interammonium distances on the mutual distances of $\mathrm{Mg}^{2+}$ in the hammerhead RNA reveals a striking correspondence between pairs of cationic centers (Figure 2). Of the congruent distances, two sets are especially remarkable, namely those at 4 and $8 \AA$, corresponding, respectively, to the distances between $\mathrm{Mg}_{(6)}^{2+}$ and $\mathrm{Mg}_{(1)}^{2+}(\sim 4 \AA)$ and between $\mathrm{Mg}_{(3)}^{2+}$ and either $\mathrm{Mg}_{(6)}^{2+}$ or $\mathrm{Mg}_{(1)}^{2+} \quad(\sim 8 \AA)$. The

abscissa, the inter $-\mathrm{Mg}^{2+}$ distances from the hammerhead RNA crystal structure are marked with broken lines. (a) Distances between the $\mathrm{Mg}^{2+}$ were recorded in simulations of the solvated hammerhead crystal structure RNA in the absence of antibiotics performed as described (Hermann et al., 1997a,b). In order to facilitate distinguishing between different $\mathrm{Mg}^{2+}$ the bars were alternately colored. Numbering of the ions is as in Figure 1(b). Intramolecular distances between ammonium groups in the aminoglycosides (b) neomycin $\mathrm{B}$, (c) tobramycin and (d) the kanamycin derivate were recorded in simulations of the solvated antibiotics. Bars indicate the dynamical range of the inter-ammonium distances (ordinate) observed at $298 \mathrm{~K}$. Numbering of the amino groups is as in Figure 1(a). Ammonium distances that correspond within a narrow range to distinct inter- $\mathrm{Mg}^{2+}$ distances are indicated in dark red. Light red bars show broad ranges of inter-ammonium distances matching several possible inter- $\mathrm{Mg}^{2+}$ distances. Light orange bars represent inter-ammonium distances with no obvious $\mathrm{Mg}^{2+}$ counterpart. 


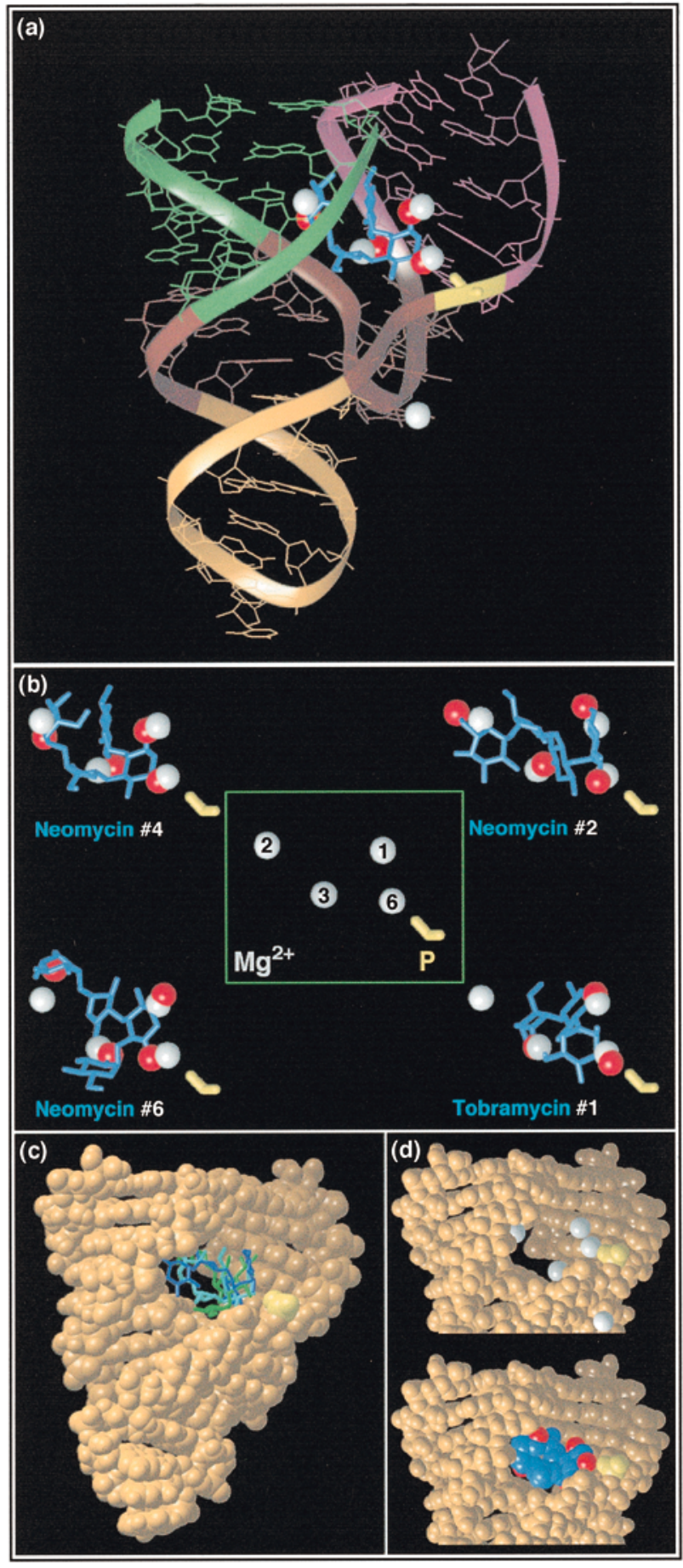

Figure 3. (a) Representative model complex obtained by docking a solution conformation of neomycin B (blue sticks; \#4 in Table 1) to the crystal structure of the hammerhead RNA. The positions of ammonium groups in the aminoglycoside that match $\mathrm{Mg}^{2+}$ (white) are marked by red spheres. The cleavable phosphate group is indicated in yellow. (b) Several different solution conformations of aminoglucoside antibiotics resulting from MD simulations display an arrangement of ammonium groups that is complementary to the position of $\mathrm{Mg}^{2+}$ in the hammerhead crystal structure. Overlay plots of the $\mathrm{Mg}^{2+}$ arrangement with three different neomycin conformers and one tobramycin structure are shown. Numbers correspond to antibiotic conformers in Table 1 . (c) Space-filling model of the hammerhead ribozyme
$\mathrm{Mg}^{2+}$ at sites 6, 3 and 1 are the three metal ions closest to the cleavable phosphate group. In the aminoglycosides, the positively charged substituents constantly separated by around $4 \AA$ are the two secondary amino groups 1 and 3 within ring $B$, positions 3 and $6^{\prime}$, and positions 3 and $2^{\prime}$ in rings $\mathrm{A}$ and $\mathrm{B}$. Corresponding pairs of amine groups with an inter-nitrogen distance of $8 \AA$ are found in various combinations for neomycin, between positions 1 and $2^{\prime}$, or 1 and $6^{\prime}$ for tobramycin, and between positions 1 and $6^{\prime \prime}, 1$ and $6^{\prime}$, or 3 and $3^{\prime \prime}$ for kanamycin. Due to the spacer pentose inserted between the amino-substituted rings B and $\mathrm{D}$ in neomycin, larger distances, resembling the separation of $\mathrm{Mg}_{(2)}^{2+}$ from the $\mathrm{Mg}^{2+}$ at sites 6, 3 and 1 , occur between amino groups.

\section{Docking of solution conformations of aminoglycosides directs ammonium groups at $\mathbf{M g}^{2+}$ binding sites in the hammerhead RNA}

To exploit the superimposition of corresponding distance pairs of ammonium groups in the aminoglycosides and $\mathrm{Mg}^{2+}$ in the hammerhead ribozyme, we evaluated whether some of the solution conformations of aminoglycosides could be docked to the hammerhead RNA in such a way that several ammonium groups occupy simultaneously the metal binding sites of the ribozyme. We selected 16 different coordinate sets from the MD trajectory of solvated neomycin, covering the conformational space accessible to the antibiotic. For tobramycin, four conformations were picked. Each of the antibiotic solution structures was docked as a rigid molecule to the hammerhead RNA crystal structure by choosing an orientation of the aminoglycoside that resulted in an optimal fit between as many as possible ammonium groups of the drug and $\mathrm{Mg}^{2+}$ positions in the ribozyme (Figure 3 ).

The resulting complexes display surprisingly good fits between the positions of the ammonium groups of the docked antibiotics and the positions of three to four $\mathrm{Mg}^{2+}$ of the hammerhead RNA (Figure 3(b)). There was not a single docking orientation of best fit for the solution conformers of neomycin, but five different sets of ammonium/ magnesium correspondences were found possible (Table 1 and Figure 3(b) and (c)). For tobramycin conformers two docking orientations were found where an optimal fit of ammonium groups to metal sites was achieved without sterical clash between the drug and the RNA. Reasons for the difference between neomycin and tobramycin are

with three different solution conformations of neomycin B sticks modeled by superimposing ammonium groups of the drug and $\mathrm{Mg}^{2+}$ of the RNA crystal structure. (d) The cavity in the hammerhead RNA formed by the facing deep grooves of stems I and II, where four $\mathrm{Mg}^{2+}$ are located, is nicely filled by aminoglycosides while the ammonium groups (red) of the drug replace the $\mathrm{Mg}^{2+}$ (white). 
Table 1. $\mathrm{Mg}^{2+}$ /ammonium group correspondences in modeled hammerhead/aminoglycoside complexes

\begin{tabular}{|c|c|c|c|c|c|c|}
\hline & Mg1 & Mg2 & Mg3 & Mg6 & Conformations $^{\mathbf{a}}$ & $\operatorname{RMS}(\AA)^{\mathbf{b}} \mathrm{N} \leftrightarrow \mathrm{Mg}$ \\
\hline \multicolumn{7}{|l|}{ Neomycin } \\
\hline \#1 & $-{ }^{c}$ & $\mathrm{~N} 6^{\prime \prime \prime}$ & N1 & $\mathrm{N} 2^{\prime}$ & 6 & $0.66-1.05$ \\
\hline$\# 2$ & $\mathrm{~N} 6^{\prime}$ & $\mathrm{N} 6^{\prime \prime \prime}$ & N1 & $\mathrm{N} 2^{\prime}$ & 4 & $0.94-1.89$ \\
\hline \#3 & $-{ }^{c}$ & N6"' & $\mathrm{N} 2^{\prime}$ & N1 & 2 & $0.92-0.99$ \\
\hline$\# 4$ & N3 & $-{ }^{c}$ & $\mathrm{~N} 2^{\prime}$ & N1 & 1 & 0.90 \\
\hline \#5 & $-{ }^{c}$ & $\mathrm{~N} 2^{\prime \prime \prime}$ & $\mathrm{N} 2^{\prime}$ & N1 & 1 & 0.68 \\
\hline \#6 & N1 & $--^{c}$ & $\mathrm{~N} 2^{\prime}$ & N3 & 2 & $1.53-1.58$ \\
\hline \multicolumn{7}{|l|}{ Tobramycin } \\
\hline \#1 & N1 & $-{ }^{c}$ & $\mathrm{~N} 2^{\prime}$ & N3" & 2 & $0.64-0.85$ \\
\hline \#2 & N6 $6^{\prime}$ & $-{ }^{c}$ & N1 & $\mathrm{N} 2^{\prime}$ & 2 & $0.85-0.98$ \\
\hline \multicolumn{7}{|c|}{$\begin{array}{l}\text { Correspondences between } \mathrm{Mg}^{2+} \text { in the crystal structure of the hammerhead ribozyme (Scott et al., 1996) } \\
\text { and ammonium groups in solution conformations of aminoglycosides, in the modeled structures of com- } \\
\text { plexes between the hammerhead and aminoglycosides (six for neomycin and one for tobramycin). } \\
\text { a Number of possible solution conformations of the antibiotic that can be used for docking to the RNA. } \\
\text { b The RMS deviation was calculated between the coordinates of the indicated } \mathrm{Mg}^{2+} \text { in the hammerhead } \\
\text { crystal structure and the coordinates of nitrogen atoms in solution conformations of the antibiotics } \\
\text { obtained by MD simulations. } \\
\text { c Not used for docking. }\end{array}$} \\
\hline
\end{tabular}

the distinct substitution pattern of the deoxystreptamine moiety along with the increased flexibility of neomycin due to its pentose spacer between the amino-substituted B and D rings. Inspection of space-filling models of the complexes reveals that the different aminoglycoside conformers nicely fill the cavity formed by the facing deep grooves of stems I and II (Figure 3(c) and (d)). Surface area calculations of the hammerhead RNA alone and of the different neomycin complexes show that between 30 and $60 \AA^{2}$ of the van der Waals surface and between 700 and $800 \AA^{2}$ of the accessible surface of the RNA are buried upon complex formation. The electrostatic drug/RNA interactions are thus additionally stabilized by numerous van der Waals and H-bonding contacts (see Figure 3(d) and Figure 5(a)).

Among the modeled aminoglycoside/RNA complexes two classes can be distinguished. In the first class, the 2' ammonium group of ring A occupies the $\mathrm{Mg}^{2+}$ binding site 3, while in the second class, this group occupies site 6 (Table 1). Two ammonium groups, namely those at position $2^{\prime}$ in ring $A$ and position 1 in ring $B$, correspond to $\mathrm{Mg}^{2+}$ binding sites in all models. Interestingly, a variety of different hammerhead-inhibiting aminoglycoside antibiotics, however great their structural diversity, contain rings $\mathrm{A}$ and $\mathrm{B}$ with these two amino groups 1 and 2' (Stage et al., 1995; Wang \& Tor, 1997a,b; Clouet-d'Orval et al., 1995; Schroeder \& von Ahsen, 1997).

\section{MD simulations suggest that aminoglycoside ammonium groups mimic metal ions in their interactions with RNA}

As described above, complexes between aminoglycoside antibiotics and the hammerhead ribozyme were modeled by docking solution conformations of the drugs to the RNA in such a way that the ammonium groups overlay the $\mathrm{Mg}^{2+}$ binding sites. In order to study the stability of the modeled complexes and to elucidate general patterns of drug/RNA interactions, we subjected the model complexes to MD simulations. For each of the 20 different complexes a 60 ps simulation was performed in which all the non-hydrogen atoms of the RNA were fixed at their positions in the crystal structure while the docked aminoglycoside was allowed to move. By using a rigid RNA in relatively short MD trajectories, we minimized the risk of considering artefactual aminoglycoside/RNA hydrogen bonds formed only occasionally due to inaccuracies of the original docking and computational errors. However, in a longer simulation performed on one of the $20 \mathrm{drug} / \mathrm{RNA}$ complexes in which the constraints on the RNA were successively released, a constant stable binding of the aminoglycoside to the RNA was observed (data not shown).

The stability of the aminoglycoside/RNA complexes was evaluated by analysing the time-dependent hydrogen bonding patterns in the drug/RNA interaction. We differentiated between direct hydrogen bonds of aminoglycoside and RNA atoms, and hydrogen bonds mediated by a single water molecule. For neomycin, an average number of five direct and six water-mediated hydrogen bonds to the RNA were observed. Tobramycin engaged two to four direct and three to five watermediated hydrogen bonds for RNA binding. Based on the number of interactions, two of the 16 different RNA complexes of neomycin and one of tobramycin with less than two direct hydrogen bonds between the aminoglycoside and the RNA were considered unstable.

A compilation of stable drug/RNA interactions observed during the MD simulations of the complexes is shown in Figure 4. The nucleotides of the hammerhead predominantly interacting with the drugs cluster in three regions: (i) $\mathrm{C}_{17}$ and $\mathrm{A}_{1.1}$, bordering the cleavable phosphate group; (ii) $U_{7}$ and $\mathrm{G}_{8}$ in the conserved single-stranded region neighboring the U-turn; (iii) $\mathrm{C}_{1.2}, \mathrm{U}_{2.4}, \mathrm{G}_{2.3}, \mathrm{G}_{2.2}$ and $\mathrm{U}_{2.1}$ 


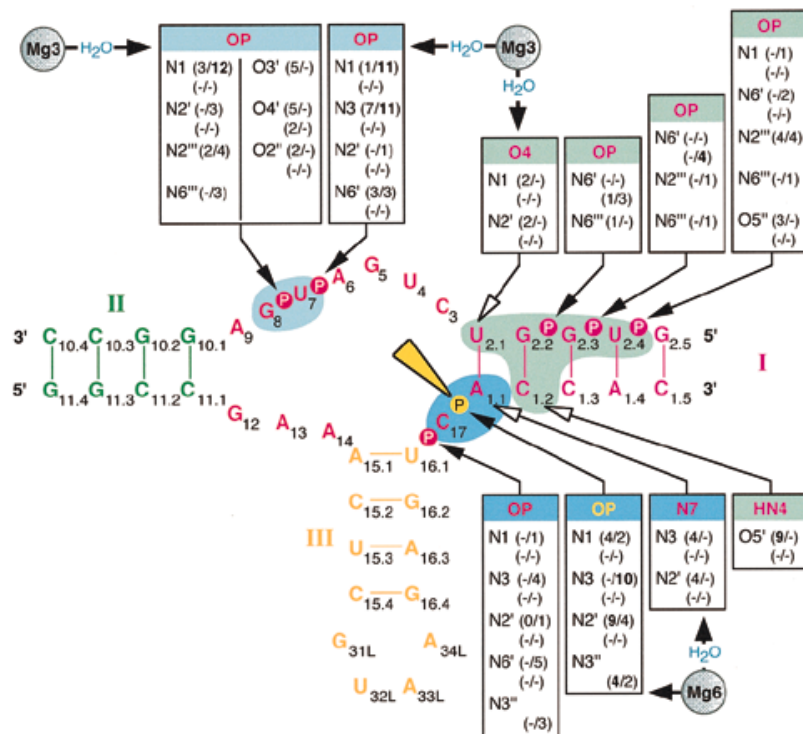

Figure 4. Overview of stable interactions observed during the MD simulations of aminoglycoside/hammerhead RNA complexes, 16 of which contained neomycin $B$ and four contained tobramycin. Coloring of the nucleotides is according to the color code in Figure 1(b). The cleavage site of the hammerhead RNA is marked in yellow. Nucleotides that interact with their base sidechains are marked with hollow arrows, those making interactions with their phosphate group are indicated by filled arrows. The respective nucleotide atom participating in interactions with the drug is given in the corresponding color on top of each box. Phosphate pro- $\mathrm{R}_{\mathrm{P}}$ and pro- $\mathrm{S}_{\mathrm{P}}$ oxygen atoms are summarized as OP. Amino and hydroxyl groups of the aminoglycosides, forming hydrogen bonds to the respective RNA atom, are listed in the boxes according to the numbering scheme of Figure 1(a). Values in parentheses indicate the number of drug/RNA complexes that displayed stable direct hydrogen bonds (first value) or interactions mediated by a stably bound water molecule (second value). The first line of values gives the results for the 16 neomycin/ RNA complexes, the second line shows the results for the four complexes containing tobramycin. Atoms are indicated that interact either directly or via a water molecule of the first hydration shell with $\mathrm{Mg}^{2+}$ in the crystal structure of the hammerhead structure (Scott et al., 1996; Hermann et al., 1997; Knöll et al., 1997).

in the non-conserved stem I. Both the number of nucleotides involved in contacts and the character of the interactions are rather similar for the different drug/RNA complexes despite the fact that the aminoglycosides are docked to the hammerhead in several distinct orientations. The nucleotides of the above-defined single-stranded regions (i) and (ii) interact with the aminoglycosides exclusively via their backbone, predominantly through phosphate groups including the cleavable phosphate group. A single prominent exception is the N7 atom of the $A_{1.1}$ base that was frequently observed forming a direct hydrogen bond to ammonium groups in the antibiotics. Of the five nucleotides within the nonconserved region (iii), $\mathrm{U}_{2.4}$ and $\mathrm{C}_{1.2}$ seem to be the
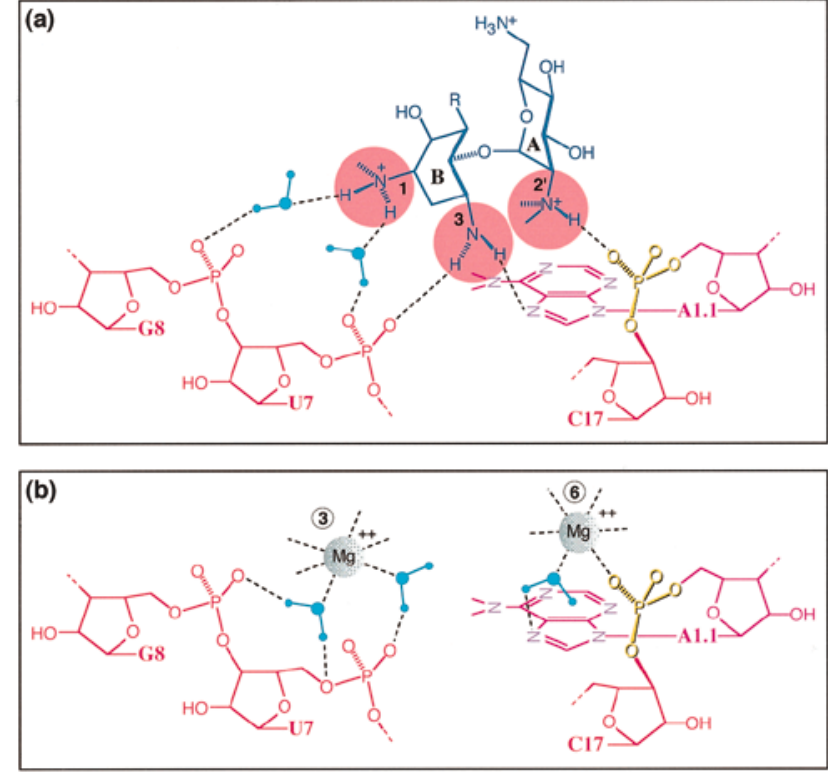

Figure 5. Comparison of the interactions between (a) the aminoglycoside neomycin B bound to the hammerhead RNA and (b) two $\mathrm{Mg}^{2+}$ in the crystal structure of the hammerhead ribozyme. Color coding of the nucleotides is as in Figures 1 and 4. The cleavable phosphate group is marked in yellow. A representative example of the different modeled complexes between neomycin and the hammerhead RNA was chosen. Hydrogen bond interactions between amino groups in the aminoglycoside (only rings A and B shown) and the RNA as observed during MD simulations are indicated by broken lines. Water molecules mediating the interactions are shown as cyan ball-and-stick triangles. (b) Coordination geometry of the $\mathrm{Mg}^{2+}$ at sites 3 and 6 of the crystral structure (Scott et al., 1996) showing the same set of nucleotides as in (a). The sites in the RNA interacting with the cationic species are essentially the same for either the (b) metal ions or (a) aminoglycoside ammonium groups.

most important hydrogen bonding partners for neomycin. $\mathrm{U}_{2.4}$ particularly engages its pro- $\mathrm{R}_{\mathrm{P}}$ phosphate oxygen atom while $C_{1.2}$ interacts exclusively via its $\mathrm{N} 4$ base amino group. In some models, a direct hydrogen bridge between the $\mathrm{O} 4$ atom of the $\mathrm{U}_{2.1}$ base and a neomycin ammonium group is found. $\mathrm{C}_{1.2}, \mathrm{U}_{2.1}$ and $\mathrm{U}_{2.4}$ play no role for interactions with tobramycin. However, in complexes with this drug, $G_{2.3}$ and $G_{2.2}$ are involved in hydrogen bonding with their pro- $\mathrm{R}_{\mathrm{P}}$ phosphate oxygen atoms.

Recent NMR studies on complexes between aminoglycoside antibiotics and either an RNA aptamer and an RNA derived from the A site of 16 S rRNA, similarly reveal the importance of direct contacts between several ammonium groups of the aminoglycosides and backbone phosphate groups of the RNA (Jiang et al., 1996; Fourmy et al., 1996). Up to three ammonium groups of tobramycin were found interacting with phosphate groups of the RNA aptamer (Jiang et al., 1996). A number of similar contacts were identified in the paromomy- 
cin/16 S rRNA complex (Fourmy et al., 1996), in line with our finding of direct contacts between hydroxyl groups of the drugs and phosphate groups of the RNA. Additional important contacts observed in our MD simulations, like the interactions between aminoglycoside ammonium groups and both purine N7 and uridine O4 atoms, were also identified in the NMR studies of drug/ RNA complexes (Jiang et al., 1996; Fourmy et al., 1996).

Striking parallels were found when comparing the regions of the hammerhead RNA interacting with aminoglycoside ammonium groups in our simulations and the RNA sites responsible for $\mathrm{Mg}^{2+}$ binding in the hammerhead crystal structure. Of the aforementioned contacts the following RNA atoms are involved in coordination of $\mathrm{Mg}^{2+}$ : the pro- $\mathrm{R}_{\mathrm{P}}$ phosphate oxygen atom and $\mathrm{N} 7$ of $\mathrm{A}_{1.1}$; phosphate oxygen atoms of $\mathrm{U}_{7}$ and $\mathrm{G}_{8} ; \mathrm{O} 4$ of the $U_{2.1}$ base (Scott et al., 1996; Hermann et al., 1997). The similarity of aminoglycoside and $\mathrm{Mg}^{2+}$ binding to the hammerhead ribozyme is illustrated by a sketch of the drug/RNA interactions observed during the MD simulations of one of the modeled complexes (Figure 5). Among the most important contacts of ammonium groups and phosphate groups are those replacing the water-mediated interactions with $\mathrm{Mg}_{(3)}^{2+}$ and the cleavage-site pro$\mathrm{R}_{\mathrm{P}}$ phosphate oxygen atom, the direct coordination of which to $\mathrm{Mg}^{2+}$ was shown both by crystal structure analysis (Scott et al., 1996) and by phosphorothioate interference analysis (Knöll et al., 1997).

\section{Discussion}

Solution conformations of the aminoglycoside antibiotics neomycin B and tobramycin could be docked to the crystal structure of a hammerhead RNA such that positively charged ammonium groups of the drugs occupy three to four $\mathrm{Mg}^{2+}$ binding sites of the ribozyme. MD simulations of the modeled complexes suggest that the interactions of the aminogylcosides with the RNA are almost identical to the interactions made by the hydrated $\mathrm{Mg}^{2+}$. Interestingly, there is not a single but several different ways to fit solution conformations of the aminoglycosides to the hammerhead metal binding sites. We propose that the structural electrostatic complementarity between the cationic groups in aminoglycosides and $\mathrm{Mg}^{2+}$ binding sites in folded RNAs is inherent to the arrangement of ammonium groups in aminoglycoside antibiotics. In these drugs, ammonium groups are predominantly located at distances of 4 and $8 \AA$ due to the geometry of the linked six-membered rings. Such distances are commonly found between $\mathrm{Mg}^{2+}$ bound to RNA or protein enzymes involved in the formation of phosphodiester bonds, e.g. polymerases (Steitz \& Steitz, 1993).

It was pointed out by Jiang and co-workers (Jiang et al., 1996) that, during their NMR study of a tobramycin/RNA aptamer complex, they were unable to identify a consistent pattern of ammonium-phosphate ionic contacts despite the fact that one to three such contacts are present in each of the refined models. This might point towards a certain diversity in the binding interaction between the aminoglycoside and the recognition pocket in the RNA. The hammerhead RNA binds aminoglycosides with lower affinity and specificity than the RNA aptamer, suggesting a less specific target for the different aminoglycoside conformers. Consequently, not a single but several different orientations of aminoglycoside conformers could be docked to the hammerhead RNA by fitting ammonium groups to metal binding sites. The diversity in the binding interaction between the drugs and the hammerhead RNA is assisted by the important number of water-mediated contacts.

The ammonium groups are singly charged and the $\mathrm{Mg}^{2+}$ doubly charged. However, the loss in pure electrostatic binding is compensated in the aminoglycosides by the entropic gain of providing all the charges simultaneously. Numerous additional van der Waals and hydrogen-bonding contacts can be formed by the substituents of the aminoglycosides due to the tight fitting of the drugs in the cavity between the stems I and II, as demonstrated by the burying of a substantial fraction of RNA surface upon complex formation.

The differences found experimentally (Clouetd'Orval et al., 1995; Wang \& Tor, 1997a,b) between the strong hammerhead inhibitor neomycin and the weaker inhibitor tobramycin are reflected in part by the different numbers of observed direct and water-mediated contacts between the drugs and the hammerhead RNA during the MD simulations. Clearly, we have found more stable interactions for neomycin than for tobramycin. However, care must be taken when concluding on macroscopic thermodynamic parameters from observations made on the very short time-scale of MD simulations. It has been recently shown (Wang \& Tor, 1997b) that the binding strength of aminoglycosides to RNA increases with the basicity of the ammonium groups, which is modulated by the adjacent hydroxyl substituents. Such subtle effects might still be beyond the limitations of the molecular mechanics approach, which uses sets of semiempirical charges. Despite this caveat, MD simulations on solvated neomycin resulted in a greater number of conformers suitable for docking to the hammerhead RNA compared to the other two drugs. This suggests that the higher inhibiting capacity of neomycin might also be due to a greater ensemble of conformers exhibiting electrostatic complementarity to the hammerhead RNA cavity.

The principle of electrostatic complementarity presented for the hammerhead ribozyme could also give an explanation for the inhibitory effect of aminoglycosides on other catalytic RNAs, like the HDV ribozyme (Rogers et al., 1996) and group I introns (von Ahsen et al., 1991). The positions of $\mathrm{Mg}^{2+}$ in the three-dimensional structure of HDV ribozyme are not known and, thus, an analysis 
similar to that performed here cannot be done. However, as for the hammerhead ribozyme, the inhibition of HDV ribozyme by aminoglycosides can be competitively reversed by increasing the concentration of $\mathrm{Mg}^{2+}$ (Rogers et al., 1996). Inhibition of group I intron self-splicing by aminoglycosides was detected as the first example of ribozyme inhibition by antibiotics (von Ahsen et al., 1991; Schroeder \& von Ahsen, 1997). Recently, it was proposed that two $\mathrm{Mg}^{2+}$ are located at a distance of $8 \AA$ in the active site of group I introns (Streicher et al., 1996). Thus, the active site $\mathrm{Mg}^{2+}$ could be replaced by cationic groups of a wide variety of aminoglycosides with their built-in interammonium distances of $8 \AA$ (I. Hoch, C. Berens, E.W., R. Schroeder, unpublished results). Interestingly, the hairpin ribozyme does not require $\mathrm{Mg}^{2+}$ for catalysis (Nesbitt et al., 1997; Young et al., 1997). However, its behavior in the presence of aminoglycosides is not reported in the literature. In any case, one would not expect an effect of aminoglycosides mechanistically comparable to that seen with the hammerhead ribozyme.

Beside catalysts of the RNA world, enzymes catalyzing the polymerization of nucleic acids contain also two $\mathrm{Mg}^{2+}$ at a distance of 4 to $5 \AA$ (Steitz \& Steitz, 1993; Joyce \& Steitz, 1995; Sousa, 1996). This was proven by $\mathrm{X}$-ray crystallographical structure determination for DNA polymerase I from Escherichia coli (Beese \& Steitz, 1991) and for the DNA polymerase $\beta$ from rat (Pelletier et al., 1994). Threedimensional structures of other polymerases like the retroviral HIV-1 reverse transcriptase (Kohlstaedt et al., 1996; Jacobo-Molina et al., 1996), the bacteriophage T7 RNA polymerase (Sousa et al., 1993) and gp43, a bacteriophage DNA polymerase of the eukaryotic pol $\alpha$ family (Wang et al., 1997) have been analyzed without resolving the active site metals. However, the universal conservation of three aspartate residues as metal coordinating ligands in the active site of polymerases (Delarue et al., 1990) along with a structurally conserved arrangement of these aspartate residues in all polymerase structures known to date make it highly likely that the geometry of two $\mathrm{Mg}^{2+}$ at a distance of approximately $4 \AA$ occurs in all polymerases.

It was pointed out before that the fact that RNA molecules can bind aminoglycosides may indicate that these antibiotics have evolved to exploit specific recognition of nucleic acids (Davies et al., 1993; Lato et al., 1995). The occurrence of similar arrangements of $\mathrm{Mg}^{2+}$ at the active sites of both ribozymes and polymerases, forming possible targets for electrostatically complementary binding of aminoglycosides, predestinates the fragments of naturally occurring aminoglycosides as versatile templates for the construction of small molecularmass effectors. The basic building blocks found in aminoglycoside antibiotics, namely six-membered rings, carrying hydroxy and amino substituents represent tailor-made synthons for the rational design of polymerase and RNA-binding inhibitors. Ammonium groups at mutual distances of around
$4 \AA$ in different structural contexts can be introduced by such single yardstick synthons. The linking of different yardstick synthons creates molecules carrying ammonium groups at $8 \AA$ distances. The large variety of possible diamino-substituted six-membered rings forms an ideal basis for the application of combinatorial chemistry in the synthesis of aminoglycoside effectors (Park et al., 1996; Wang \& Tor, 1997c).

\section{Methods}

\section{Force-field parameters for RNA and aminoglycoside antibiotics}

Aminoglycoside models (Figure 1(a)) were built using the Insight software (Biosym Technologies, San Diego) based on NMR data on tobramycin bound to an RNA aptamer (Jiang et al., 1996) and on X-ray structure data of kanamycin (Koyama et al., 1996). Force field parameters for the antibiotics were derived as previously described (Hermann \& Heumann, 1995). Atom coordinates of the hammerhead RNA were from a recently published crystal structure analysis (Scott et al., 1996). Parameters for $\mathrm{Mg}^{2+}$ were from Âquist (1990).

\section{MD simulations}

The AMBER4.1 package (Pearlman et al., 1994) was used for MD simulations. Calculations were done with a time-step of $1 \mathrm{fs}$ at a constant pressure of $1 \mathrm{~atm}$. The van der Waals interactions were truncated at $9.0 \AA$, while no cut-off was applied on the electrostatic term. The electrostatic interactions were calculated with the Particle Mesh Ewald method (Darden et al., 1993). MD simulations of the solvated hammerhead crystal structure RNA in the absence of antibiotics were performed as described (Hermann et al., 1997, 1998).

\section{Simulations of solvated aminoglycosides}

The antibiotic was placed in a rectangular box of SPC/E water (Berendsen et al., 1987) containing about 600 solvent molecules. $\mathrm{Cl}^{-}$counterions were placed according to the electrostatic potential around the antibiotic. After 1000 steps of conjugate gradient minimization, 10 ps of solvent equilibration MD at $298 \mathrm{~K}$ were run with non-hydrogen atoms of the antibiotic fixed. Then, all constraints were removed, and starting from $10 \mathrm{~K}$ the system was heated to $298 \mathrm{~K}$ over a period of 18 ps followed by 50 ps of productive simulation at this temperature. Subsequently, 16 rounds of high-temperature MD were performed where in each cycle the system was kept at $600 \mathrm{~K}$ over $10 \mathrm{ps}$ followed by 10 ps simulation at $298 \mathrm{~K}$. Conformations were sampled every 0.5 ps. For distance measurements between amino groups, only conformations obtained at $298 \mathrm{~K}$ were considered.

\section{Docking of aminoglycosides to the hammerhead RNA}

Conformations were extracted from the MD trajectory of solvated antibiotics at the end of the $298 \mathrm{~K}$ phases. Docking of rigid aminoglycosides to the hammerhead RNA was performed by least-squares fitting of ammonium nitrogen atoms of the antibiotic to $\mathrm{Mg}^{2+}$ pos- 
itions in the RNA crystal structure. All possible permutations of ammonium/magnesium correspondences were checked for each antibiotic conformer. In each case, we selected the complex with the lowest deviation while at the same time assuring that no significant sterical clash between the antibiotic and the RNA occurred. Coordinates of a set of representative aminoglycoside/ hammerhead complexes are avaible via anonymous ftp (130.79.17.244). Molecular surface area calculations were done with GRASP (Nicholls et al., 1991).

\section{MD simulations of antibiotic/RNA complexes}

Each aminoglycoside/RNA complex was placed in a rectangular box of SPC/E water containing about 2500 solvent molecules. $\mathrm{Na}^{+}$counterions were placed according to the electrostatic potential around the complex such that no ion was closer than $4.5 \AA$ to any solute atom. In all steps of the following calculations the nonhydrogen atoms of the RNA were fixed at their positions in the crystal structure. Initially 1000 steps of conjugate gradient minimization were performed followed by 10 ps of solvent equilibration MD at $298 \mathrm{~K}$ with heavy atoms of the aminoglycoside fixed. Subsequently, the constraints on the antibiotic were removed, and the system was heated from $10 \mathrm{~K}$ to $298 \mathrm{~K}$ in steps of $50 \mathrm{~K}$ over a period of 15 ps: 60 ps of productive MD followed. The MD trajectories were analyzed by time-averaged evaluation of hydrogen bonding between the antibiotic and the RNA.

\section{Acknowledgments}

We thank R. Schroeder (Vienna Biocenter) for continuing discussions on RNA-antibiotics interactions and Y. Tor (UCSD) for communicating results before publication. We are also thankful to M. Famulok (Genzentrum, LMU München) for careful reading of the manuscript. We are much indebted to Peter Kollman and his group at UCSF for making available to us the latest version of the AMBER package used in the present study. T.H. is supported by an EMBO long-term fellowship.

\section{References}

von Ahsen, U., Davies, J. \& Schroeder, R. (1991). Antibiotic inhibition of group I ribozyme function. Nature, 353, 368-370.

Åqvist, J. J. (1990). Ion-water interaction potentials derived from free energy perturbation simulations. Phys. Chem. 94, 8021-8024.

Beese, L. S. \& Steitz, T. A. (1991). Structural basis for the $3^{\prime}-5^{\prime}$ exonuclease activity of E. coli DNA polymerase $\mathrm{I}$ : a two metal ion mechanism. EMBO J. 10, 25-33.

Berendsen, H. J. C., Grigera, J. R. \& Straatsma, T. P. (1987). The missing term in effective pair potential. J. Phys. Chem. 97, 6269-6271.

Botto, R. E. \& Coxon, B. (1983). Nitrogen-15 nuclear magnetic resonance spectroscopy of neomycin B and related aminoglycosides. J. Am. Chem. Soc. 105, 1021-1028.

Clouet-d'Orval, B., Stage, T. K. \& Uhlenbeck, O. C. (1995). Neomycin inhibition of the hammerhead ribozyme involves ionic interactions. Biochemistry, 34, 11186-11190.
Dahm, S. C. \& Uhlenbeck, O. C. (1991). Role of divalent metal ions in the hammerhead RNA cleavage reaction. Biochemistry, 30, 9464-9469.

Darden, T. A., York, D. \& Pedersen, L. G. (1993). Particle Mesh Ewald: an N. $\log N$ method for Ewald sums in large systems. J. Chem. Phys. 98, 1008910092.

Davies, J., von Ahsen, U. \& Schroeder, R. (1993). Antibiotics and the RNA world: a role for low-molecular-weight effectors in biochemical evolution? In The RNA World (Gesteland, R. F. \& Atkins, J. F., eds), pp. 185-204, Cold Spring Harbor Laboratory Press, Cold Spring Harbor, NY.

Delarue, M., Poch, O., Tordo, N., Moras, D. \& Argos, P. (1990). An attempt to unify the structure of polymerases. Protein Eng. 3, 461-467.

Famulok, M. \& Hüttenhofer, A. (1996). In vitro selection analysis of neomycin binding RNAs with a mutagenized pool of variants of the $16 \mathrm{~S}$ rRNA decoding region. Biochemistry, 35, 4265-4270.

Fourmy, D., Recht, M. I., Blanchard, S. C. \& Puglisi, J. D. (1996). Structure of the A site of E. coli 16 S ribosomal RNA complexed with an aminoglycoside antibiotic. Science, 274, 1367-1371.

Gale, E. F., Cundliffe, E., Reynolds, P. E., Richmond, M. H. \& Waring, M. H. (1981). The Molecular Basis of Antibiotic Action, Wiley, New York.

Hendrix, M., Priestley, E. S., Joyce, G. F. \& Wong, C.-H. (1997). Direct observation of aminoglycoside-RNA interaction by surface plasmon resonance. J. Am. Chem. Soc. 119, 3641-3648.

Hermann, T. \& Heumann, H. (1995). Determination of nucleotide distances in RNA by means of copper phenanthroline-generated hydroxyl radical cleavage pattern. RNA, 1, 1009-1017.

Hermann, T., Auffinger, P., Scott, W. G. \& Westhof, E. (1997). Evidence for a hydroxide ion bridging two magnesium ions at the active site of the hammerhead ribozyme. Nucl. Acids Res. 25, 3421-3427.

Hermann, T., Auffinger, P. \& Westhof, E. (1998). Molecular dynamics investigations of hammerhead ribozyme RNA. Eur. Biophys. J. 27, in the press.

Jacobo-Molina, A., Ding, J., Nanni, R. G., Clark, A. D., Lu, X., Tantillo, C., Williams, R. L., Kamer, G., Ferris, A. L., Clark, C., Hizi, A., Hughes, S. H. \& Arnold, E. (1993). Crystal structure of human immunodeficiency virus type 1 reverse transcriptase complexed with double-stranded DNA at 3. $0 \AA$ resolution shows bent DNA. Proc. Natl Acad. Sci. USA, 89, 10763-10767.

Jiang, L., Suri, A. K., Fiala, R. \& Patel, D. J. (1996). Saccharide-RNA recognition in an aminoglycoside antibiotic-RNA aptamer complex. Chem. Biol. 4, 3550 .

Joyce, C. M. \& Steitz, T. A. (1995). Polymerase structures and function-variations of a theme. J. Bacteriol. 177, 6321-6329.

Knöll, R., Bald, R. \& Fürste, J. P. (1997). Complete identification of nonbridging phosphate oxygens involved in hammerhead cleavage. RNA, 3, 132-140.

Kohlstaedt, L. A., Wang, J., Friedman, J. M., Rice, P. A. \& Steitz, T. A. (1992). Crystal structure at $3.5 \AA$ resolution of HIV-1 reverse transcriptase complexed with an inhibitor. Science, 256, 1783-1790.

Koyama, G., Iitaka, Y., Maeda, K. \& Umezawa, H. (1968). The crystal structure of kanamycin. Tetrahedron Letters, 15, 1875-1879.

Lato, S. M., Boles, A. R. \& Ellington, A. D. (1995). In vitro selection of RNA lectins: using combinator- 
ial chemistry to interpret ribozyme evolution. Chem. Biol. 2, 291-303.

Long, D. M., LaRiviere, F. J. \& Uhlenbeck, O. C. (1995). Divalent metal ions and the internal equilibrium of the hammerhead ribozyme. Biochemistry, 34, 1443514440.

Moazed, D. \& Noller, H. F. (1987). Interaction of antibiotics with functional sites in $16 \mathrm{~S}$ ribosomal RNA. Nature, 327, 389-394.

Nesbitt, S., Hegg, L. A. \& Fedor, M. J. (1997). An unusual $\mathrm{pH}$-independent and metal-ion-independent mechanism for hairpin ribozyme catalysis. Chem. Biol. 4, 619-630.

Nicholls, A., Sharp, K. A. \& Honig, B. H. (1991). Protein folding and association: insights form the interfacial and thermodynamic properties of hydrocarbons. Proteins: Struct. Funct. Genet. 11, 281-296.

Park, W. K. C., Auer, M., Jaksche, H. \& Wong, C.-H. (1996). Rapid combinatorial synthesis of aminoglycoside antibiotic mimetics: use of a polyethylene glycol-linked amine and a neamine-derived aldehyde in multiple component condensation as a strategy for the discovery of new inhibitors of the HIV RNA Rev responsive element. J. Am. Chem. Soc. 118, 10150-10155.

Pearlman, D. A., Case, D. A., Caldwell, J. W., Ross, W. S., Cheatham, T. E., DeBolt, S., Ferguson, D., Seibel, G., Singh, U. C., Weiner, P. K. \& Kollman, P. A. (1994). AMBER 4. 1, San Francisco, California.

Pelletier, H., Sawaya, M. R., Kumar, A., Wilson, S. H. \& Kraut, J. (1994). Structures of ternary complexes of rat DNA polymerase $\beta$, a template-primer, and ddCTP. Science, 264, 1891-1903.

Pley, H. W., Flaherty, K. M. \& McKay, D. B. (1994). Three-dimensional structure of a hammerhead ribozyme. Nature, 372, 68-74.

Rogers, J., Chang, A. H., von Ahsen, U., Schroeder, R. \& Davies, J. (1996). Inhibition of the self-cleavage reaction of the human hepatitis delta virus ribozyme by antibiotics. J. Mol. Biol. 259, 916-925.

Schroeder, R. \& von Ahsen, U. (1996). Interaction of aminoglycoside antibiotics with RNA. Nucl. Acids Mol. Biol. 10, 53-74.

Scott, W. G., Finch, J. T. \& Klug, A. (1995). The crystal structure of an all-RNA hammerhead ribozyme: a proposed mechanism for RNA catalytic cleavage. Cell, 81, 991-1002.

Scott, W. G., Murray, J. B., Arnold, J. R. P., Stoddard, B. L. \& Klug, A. (1996). Capturing the structure of a catalytic RNA intermediate: the hammerhead ribozyme. Science, 274, 2065-2069.

Sousa, R. (1996). Structural and mechanistic relationships between nucleic acid polymerases. Trends Biochem. Sci. 21, 186-190.
Sousa, R., Chung, Y. J., Rose, J. P. \& Wang, B. C. (1993). Crystal structure of bacteriophage T7 RNA polymerase at 3. $3 \AA$ resolution. Nature, 364, 593-599.

Stage, T. K., Hertel, K. J. \& Uhlenbeck, O. C. (1995). Inhibition of the hammerhead ribozyme by neomycin. RNA, 1, 95-101.

Steitz, T. A. \& Steitz, J. A. (1993). A general two-metalion mechanism for catalytic RNA. Proc. Natl Acad. Sci. USA, 90, 6498-6502.

Streicher, B., Westhof, E. \& Schroeder, R. (1996). The environment of two metal ions surrounding the splice site of a group I intron. EMBO J. 15, 25562564.

Szilagyi, L., Pusztahelyi, Z. S., Jakab, S. \& Kovacs, I. (1993). Microscopic protonation constants in tobramycin: An NMR and pH study with the aid of partially N-acetylated derivatives. Carbohydr. Res. 247, 99-109.

Wallis, M. G., von Ahsen, U., Schroeder, R. \& Famulok, M. (1995). A novel RNA motif for neomycin recognition. Chem. Biol. 2, 543-552.

Wang, H. \& Tor, Y. (1997a). Electrostatic interactions in RNA-aminoglycosides binding. J. Am. Chem. Soc. 119, 8734-8735.

Wang, H. \& Tor, Y. (1997b). RNA-aminoglycoside interactions: the design, synthesis and RNA binding of "amino-aminoglycosides". Angew. Chem. in the press.

Wang, H. \& Tor, Y. (1997c). Dimeric aminoglycosides: design, synthesis and RNA binding. Bioorg. Med. Chem. Letters, 7, 1951-1956.

Wang, J., Sattar, A. K. M. A., Wang, C. C., Karam, J. D., Konigsberg, W. H. \& Steitz, T. A. (1997). Crystal structure of a pol $\alpha$ family replication DNA polymerase from bacteriophage RB69. Cell, 89, 10871099.

Wang, Y. \& Rando, R. R. (1995). Specific binding of aminoglycoside antibiotics to RNA. Chem. Biol. 2, 281290.

Werstuck, G., Zapp, M. L. \& Green, M. R. (1996). A non-canonical base pair within the human immunodeficiency virus Rev-responsive element is involved in both Rev and small molecule recognition. Chem. Biol. 3, 129-137.

Young, K. J., Gill, F. \& Grasby, J. A. (1997). Metal ions play a passive role in the hairpin ribozyme catalysed reaction. Nucl. Acids Res. 25, 3760-3766.

Zapp, M. L., Stern, S. \& Green, M. R. (1993). Small molecules that selectively block RNA binding of HIV-1 Rev protein inhibit Rev function and viral production. Cell, 74, 969-978.

Edited by J. Karn 